\title{
A HABITAÇÃO DE INTERESSE SOCIAL COMO ESTRATÉGIA DE PRESERVAÇÃO DA MEMÓRIA
}

MEDINA, LUCIANO LACERDA

Doutor em Desenvolvimento Urbano, Professor Adjunto do Departamento de Arquitetura e Urbanismo da UFPE, II.medina@globo.com

\author{
LIMA, ANDREYNA R. S. CORDEIRO DE
}

Arquiteta e colaboradora na A+R Arquitetos, andreynasena@gmail.com

\section{ALBUQUERQUE, THULYA A. GONÇALVES DE}

Arquiteta e colaboradora na A+R Arquitetos, thulyaalbuquerque@hotmail.com

\section{OLIVEIRA, RODRIGO CÂNDIDO DE}

Aluno do Curso de Arquitetura e Urbanismo da UFPE e estagiário na A+R Arquitetos, rodrigocann@gmail.com

\section{RESUMO}

Este é um projeto de Arquitetura que apresentamos no Prêmio Armando Holanda, organizado pelo Conselho de Arquitetura e Urbanismo - seção Pernambuco neste final de 2018. Em se tratando de um projeto, constitui-se mais por uma ideia que eventualmente nos aproveitamos de uma situação concreta - neste caso aplicada ao bairro do Pilar em Salvador, na Bahia - para ilustrar e apresentar algumas de nossas reflexões. Reflexões estas aplicadas em outros contextos e concursos, inclusive. Todavia, nunca antes as evidenciamos pelos aspectos propagados por Armando Holanda para uma Arquitetura situada no Nordeste do Brasil. Daí que não podemos esconder certa surpresa pelo reconhecimento do júri por uma proposta que também se fundamentou na questão do Patrimônio Arquitetônico e pela memória dos lugares. A nossa proposição só pode ser entendida como ideia, como estratégia, ao invés de uma solução definitiva para um caso específico. Uma estratégia de preservação e de uso das ruínas dos velhos sobrados do Pilar como verdadeiras 'mascaras de sombreamento', proteção e resguardo de uma nova escala espacial dentro da cidade tradicional. Os terrenos escolhidos para a nossa proposta integram o que a Prefeitura de Salvador já denominou como Projeto de Requalificação Urbana do Pilar, próxima ao Porto de Salvador. O Pilar constitui uma área remanescente da morfologia urbana original da cidade de Salvador. Antigos sobrados, implantados em lotes estreitos e alongados, justapostos uns aos outros, conformando uma solução estrutural solidária, que ocupam os morros dessa área definindo estreitas ruas e vielas ao longo das suas curvas de nível. 0 texto constitui o Memorial Explicativo da proposta.

PALAVRAS-CHAVE: arquitetura nordestina; arquitetura urbana; patrimônio

\section{RESUMEN}

Estudio teórico y empírico sobre la percepción visual y las habilidades asistenciales de salud (EAS) de la Red Sarah Kubitschek en Brasilia. Las condiciones de confort visual para el medio de vesiculo EAS - el Hospital Sarah Kubitschek Enfermedades del Aparato Locomotor y Hospitalario Sarah Kubitschek Centro de Rehabilitación en comparación con el Hospital Regional de la Asa Norte (HRAN), todas en Brasilia. Una investigación pretendía proporcionar parámetros para la definición de las variables de proyecto relacionadas al confort visual que poseen el mismo proceso, evidenciando una interacción entre la arquitectura, la forma y la utilización y el usuario en la formación de un instrumento de curación. Metodología utilizada en el análisis de EAS recurrió a: (1) una revista post-ocupación (APO), para investigar la percepción visual de los usuarios del espacio; (2) una evaluación técnica basada en la Teoría de la Gestalt, con el fin de generar un Índice de Confort Visual. Lo que es espacial, ambiental, espacial, estético, comodidad y calidad de los EAS. Los resultados fueron las condiciones de confort visual de los hospitales de la Red Sarah son muy satisfactorias, en contrapartida al HRAN, más recientemente negativamente. El conjunto de informaciones analizadas puede subsidiar la elaboración de nuevos proyectos de internación hospitalaria en minimizar la incomodidad de los pacientes a través de la arquitectura de alto nivel, asi como el ambiente como estimulador de acciones.

PALABRAS CLAVE: arquitectura hospitalaria, luz y color, percepción visual y teoría de la Gestalt.

\section{ABSTRACT}

This is an Architecture project that we present at the Armando Holanda Prize, organized by the Architecture Council - Pernambuco section - at the end of 2018. When it comes to a project, it is more of an idea that eventually we take advantage of a concrete situation - in this case applied to the district of Pilar in Salvador, Bahia - to illustrate and present some of our reflections. Reflections are applied in other contexts and until other contests. However, we have never before shown them by the aspects propagated by Armando Holanda for an Architecture located in Northeast Brazil. Therefrom we can not hide a certain surprise by the recognition of the jury by a proposal that also was based on the question of the Architectural Patrimony and by the memory of the places. Our proposition can only be understood as an idea, as a strategy and not like a definitive solution to a specific case. A strategy of preserving and using the ruins of the old Pilar houses as true 'masks of shading', protection and protection of a new spatial scale within the Traditional City. The land chosen for our proposal is part of what the City of Salvador has already called the Pilar Urban Renewal Project, near the Harbour of Salvador. The Pilar is a remnant area of the original urban morphology of the city of Salvador. Old houses, implanted in narrow and elongated lots, juxtaposed one another, conforming a solidary structural solution that occupy the hills of this area defining narrow streets and alleys along their contour lines. The text constitutes the Explanatory Memorandum of the proposal.

KEYWORDS: northeastern architecture; urban architecture; patrimony 


\section{INTRODUÇÃO}

Desde 2006, estudamos o 'caso' da área do bairro Pilar, em Salvador. Fosse por sua situação no contexto urbano da 'velha Salvador' - em um processo acelerado de transformação em grande ruína -, fosse por sua situação de localização sui generis: numa cota à cavaleiro de vistas da paisagem da Baía de Todos os Santos, cuja beleza é confrontada por uma orientação de poente - em razão da morfologia da baía e da cidade. Se a paisagem natural e urbana da cidade tradicional requer que as fachadas dos velhos sobrados abram seus 'olhos' para as ruas do antigo e velho Pilar, a orientação e requisitos do conforto ambiental mais modernos - pedem que se 'negue' isso. O que fazer?

A nossa proposição deve ser avaliada muito mais como uma ideia, uma estratégia do que como uma solução definitiva para um caso específico. Uma estratégia de preservação e de uso das ruínas dos velhos sobrados como verdadeiras 'mascaras de sombreamento', proteção e, também, resguardo de uma nova escala espacial dentro da cidade tradicional.

\section{PROBLEMA}

Os terrenos escolhidos para a nossa proposta integram o que a Prefeitura de Salvador já denominou como Projeto de Requalificação Urbana do Pilar, próxima ao Porto de Salvador. O Pilar constitui uma área remanescente da morfologia urbana original da cidade de Salvador. Antigos sobrados, implantados em lotes estreitos e alongados, justapostos uns aos outros, conformando uma solução estrutural solidária que ocupam os morros dessa área definindo estreitas ruas e vielas ao longo das suas curvas de nível (Figura 1).

Essa tipologia de sobrados erigidos no paramento da rua com paredes espessas de adobes revestidos em suas fachadas, possuíam em seu espaço interior compartimentos divididos por paredes mais finas, elevados em vários pavimentos - de 4 até mesmo 6 pavimentos. Pavimentos estes construídos em estrutura de vigas de madeira assoalhadas em tábuas. Para assegurar sua solidez estrutural, esses casarões eram construídos justapostos uns aos outros, numa típica morfologia urbana portuguesa.

O tempo impôs seus efeitos sobre a área do Pilar. As ruínas vão aos poucos se sucedendo, deixando ainda algumas marcas e lembranças de um outro tempo. A estrutura mais frágil do interior dessas construções vai lentamente desmoronando, restando quase sempre suas fachadas de construção mais robusta. Contudo, em razão da surpreendente verticalização dessas, aos poucos elas também desmoronam pela falta de elementos construtivos que possibilitem o seu contraventamento (Figura 2).

A construção de novas habitações de melhor condição e qualidade, na área do Pilar, pode constituir uma oportunidade de promover uma requalificação ambiental, além de preservar, com dignidade, as reminiscências urbanas de uma antiga Salvador.

\section{A IDEIA: O NOVO E O ANTIGO E UMA CONVIVÊNCIA QUE DEFINE NOVOS ESPAÇOS URBANOS}

Propomos uma ideia muito simples: inserir novas construções no espaço interior das velhas ruínas e construções, criando espaços intersticiais entre as duas construções. Estes espaços não constituiriam simples afastamentos, mais espaços de convívio, como pátios internos para moradores e galerias urbanas para os transeuntes da cidade conferindo espaços de proteção ambiental e térmica, já que boa parte dos morros do Pilar se debruçam sobre a Baía de Todos os Santos numa orientação solar predominantemente poente (Figuras 3 e 5).

Esses espaços seriam desenhados conforme a implantação das novas construções, resultantes da escolha pela melhor situação urbana, já que as antigas fachadas conservam a função de definição das ruas desta tradicional morfologia.

As velhas fachadas e ruínas seriam reestruturadas e apoiadas sobre as novas construções e manter-se-iam como elementos construtivos que definem o espaço da rua tradicional, protegeriam as fachadas das novas construções erigidas em sua retaguarda de insolações eventualmente desfavoráveis e constituiriam espaços e galerias urbanas mediando a relação entre o público e o privado. Muito embora estejam agora desprovidas de sua função utilitária primordial, elas passariam a exercer uma função simbólica, reverencial e protetora.

As novas construções, esses novos edifícios habitacionais, estabeleceriam uma espécie de simbiose arquitetônica em prol da memória do lugar. 


\section{A SUSTENTABILIDADE AMBIENTAL, SOCIAL E ECONÔMICA [HIS+COMÉRCIO]}

A nossa proposta-exemplar foi desenhada para os lotes 39, 21, 23, 25, 27 e 29 da rua Caminho Novo do Taboão, no Pilar para ilustrar a nossa ideia. Elaboramos um projeto para um edifício habitacional que, na verdade, configura mais de um.

O edifício constitui-se de quatro partes, implantadas de modo a configurar espaços intersticiais para uma galeria urbana e pátio interno de convívio e de sombreamento para as novas habitações. Uma parte do edifício constitui unidades de dois quartos com 40m2, e tem ao todo nove pavimentos e um teto-jardim. Outra parte constitui a Sobreloja e Lojas deste mesmo edifício. Essa área comercial tem forte e direta relação com a Galeria Urbana que media a relação do conjunto com a rua. Uma outra parte do edifício constitui um bloco de quatro pavimentos com unidade habitacionais de um quarto e 30m2 de área. $\mathrm{O}$ 'falso térreo' deste bloco está formado por quatro lojas de médio porte abertas para uma Galeria Urbana formada pelo afastamento deste em relação ao primeiro e constitui a quarta parte do conjunto. Sob o piso desta Galeria propomos uma garagem e área para equipamentos (Figuras 3 a 6).

A definição altimétrica do novo conjunto foi definida em razão da relação com as antigas fachadas [lotes 23 a 29] e do que outrora foram as construções dos lotes 39 e 21, de modo que os novos edifícios não sobrepujassem a escala da antiga cidade e a premissa de não alterar a geomorfologia do morro que faz o 'fundo íngreme' para com esses imóveis - a intervenção direta sobre os morros poderia permitir o aumento de área construída, todavia em razão da sua declividade acentuada, isto só seria possível com a construção de extensos e robustos arrimos que poderiam inviabilizar economicamente a construção de novas unidades.

A definição do uso misto para o conjunto permitiria manter os custos de manutenção das áreas condominiais, especialmente se algumas das lojas forem administradas pelo condomínio. Isto é imprescindível para a sustentabilidade econômica do conjunto, já que as áreas condominiais de convívio são muito importantes para a qualificação do projeto, mas significam custos que necessitam de amortização. Assim como o uso comercial trará a devida e desejada animação urbana ao contexto urbano próximo ao conjunto.

\section{CONSIDERAÇÕES FINAIS - A TECNOLOGIA CONSTRUTIVA À SERVIÇO DA CIDADE}

Os princípios de projeto e desenho que, em nosso entendimento, devem qualificar a solução arquitetônica e urbanística habitacional são a [i] excelência do sistema construtivo [segurança, acabamento, relação custobenefício, relação entre padronização e especificidade]; [ii] padrões dignos e aceitáveis de conforto e habitabilidade das unidades habitacionais; [iii] a proposição de espaços de convívio e encontros, valorizando a vida em comunidade; [iv] o direito à Arquitetura e à Estética; e o mais importante de todos: a solução de arquitetura por mais padronizada que possa ser a tecnologia construtiva empregada, [v] deve primar pela integração do projeto com o contexto urbano imediato e, sobretudo constituir-se numa oportunidade de [re]desenhar a Cidade - de prover uma 'estética urbana'. Assim, esta urbanidade da solução arquitetônica deverá constituir-se em um sinal de respeito ao maior de todos os artefatos e a maior de todas as instituições criadas pelo homem que é a cidade.

Escolhemos um sistema construtivo e estrutural moderno, de relativo baixo-custo [elimina o uso de formas, possui baixíssimo desperdício], durável, prima pela padronização e coordenação modular, garante a perfeita execução de prumos, segurança, baixo custo de manutenção e rapidez de execução e pode ser integrado de maneira ágil e fácil aos softwares que possuem Plataformas BIM. Trata-se da Alvenaria Armada em Blocos de Concreto e Lajes Alveolares de Concreto Pré-Moldadas. Todavia, a primazia deste sistema construtivo no uso da coordenação modular permite que ele possa ser facilmente adaptado para um sistema de pré-fabricação em painéis de forma de concreto ou até mesmo para o uso do aço.

A escolha do sistema construtivo e estrutural, permitiu que fossem definidas Unidades Habitacionais, cujo vão estrutural seria de $7.50 \mathrm{~m}$. Isto permite que todas as paredes internas constituam simples divisórias, portanto, utilizando-se blocos de alvenaria mais estreitos, liberando maior área útil para os ambientes e criando alternativas de novos layouts. Para garantir ainda uma melhor habitabilidade das unidades habitacionais, as divisórias longitudinais e as esquadrias de vedação externas - cuja caixilharia poderia ser em aço galvanizado e do tipo basculante - possuem na parte superior um faixa de elementos vazados de modo a facilitar a circulação cruzada, retirando mais rapidamente o excesso de vapor d'água dos ambientes. A alvenaria de concreto armada permitiria, também, a construção eficiente e com menores custos dos arrimos de contenção, assim como a estrutura de encamisamento das antigas e reminiscentes fachadas. 
Medina, L. L.; Lima, A R. S. C.; Albuquerque, T. A. G.; Oliveira, R. C.

Figura 1: Imagens do Painel 1/3 do Concurso
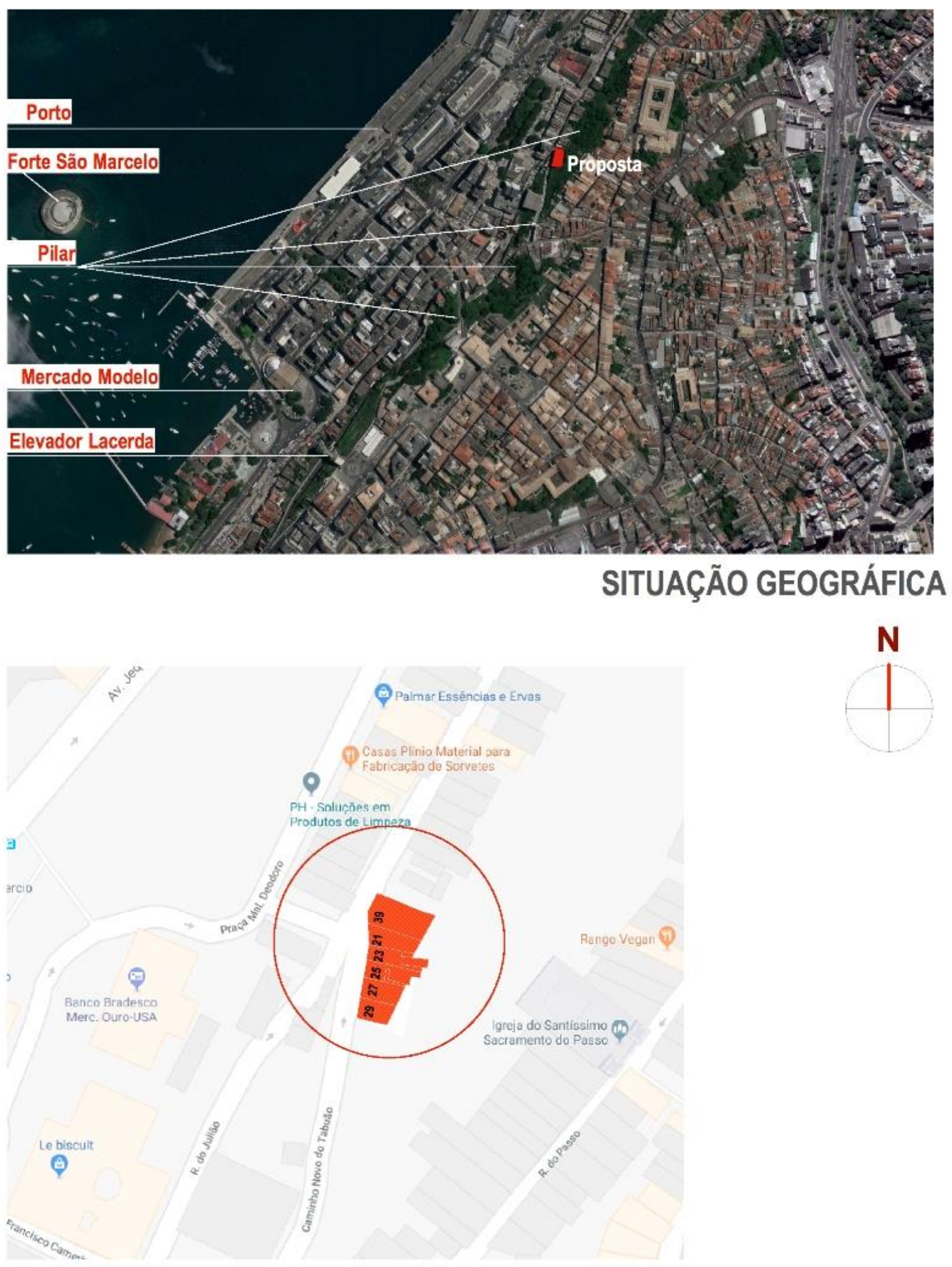

Fonte: Elaboração dos autores sobre imagens do Google Earth 
Medina, L. L.; Lima, A R. S. C.; Albuquerque, T. A. G.; Oliveira, R. C.

Figura 2: Imagens do Painel 1/3 do Concurso

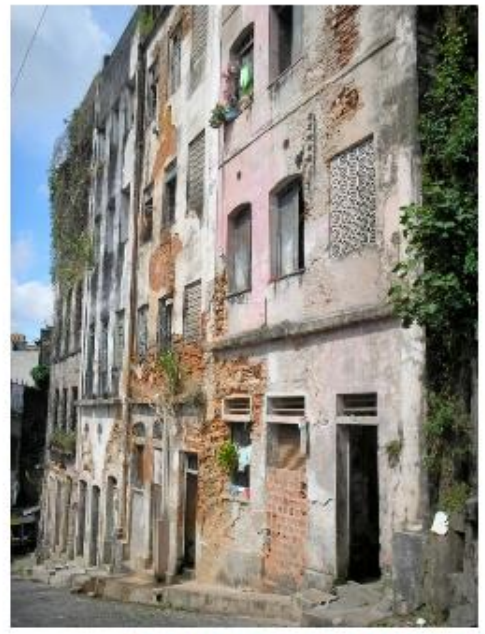

As ruínas aos poucos vão se sucedendo no Pilar, formando uma paisagem de reminiscências de uma memorável e antiga Salvador
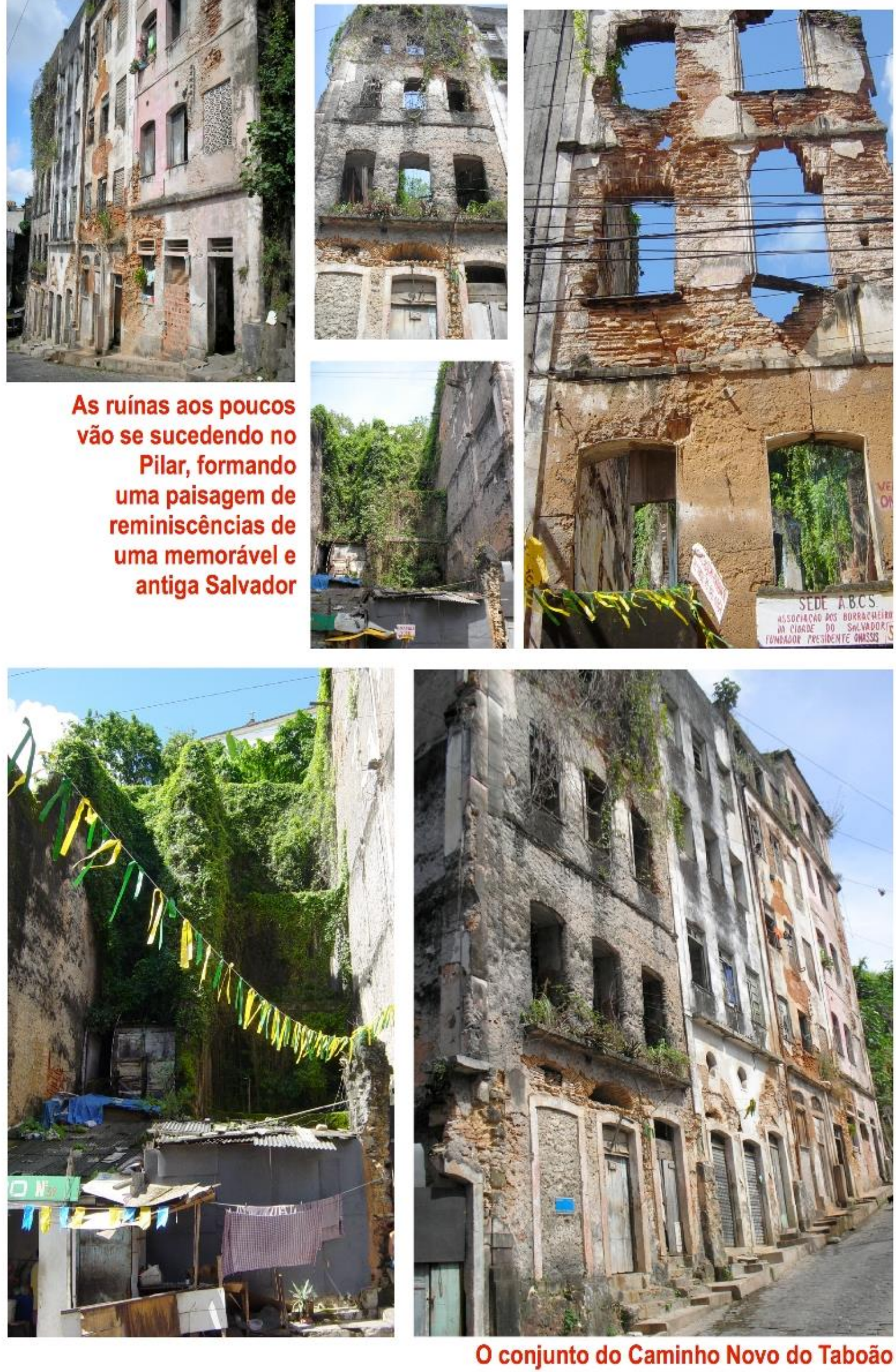

Fonte: Fotos dos autores 
Medina, L. L.; Lima, A R. S. C.; Albuquerque, T. A. G.; Oliveira, R. C.

Figura 3: Imagens do Painel 2/3 do Concurso

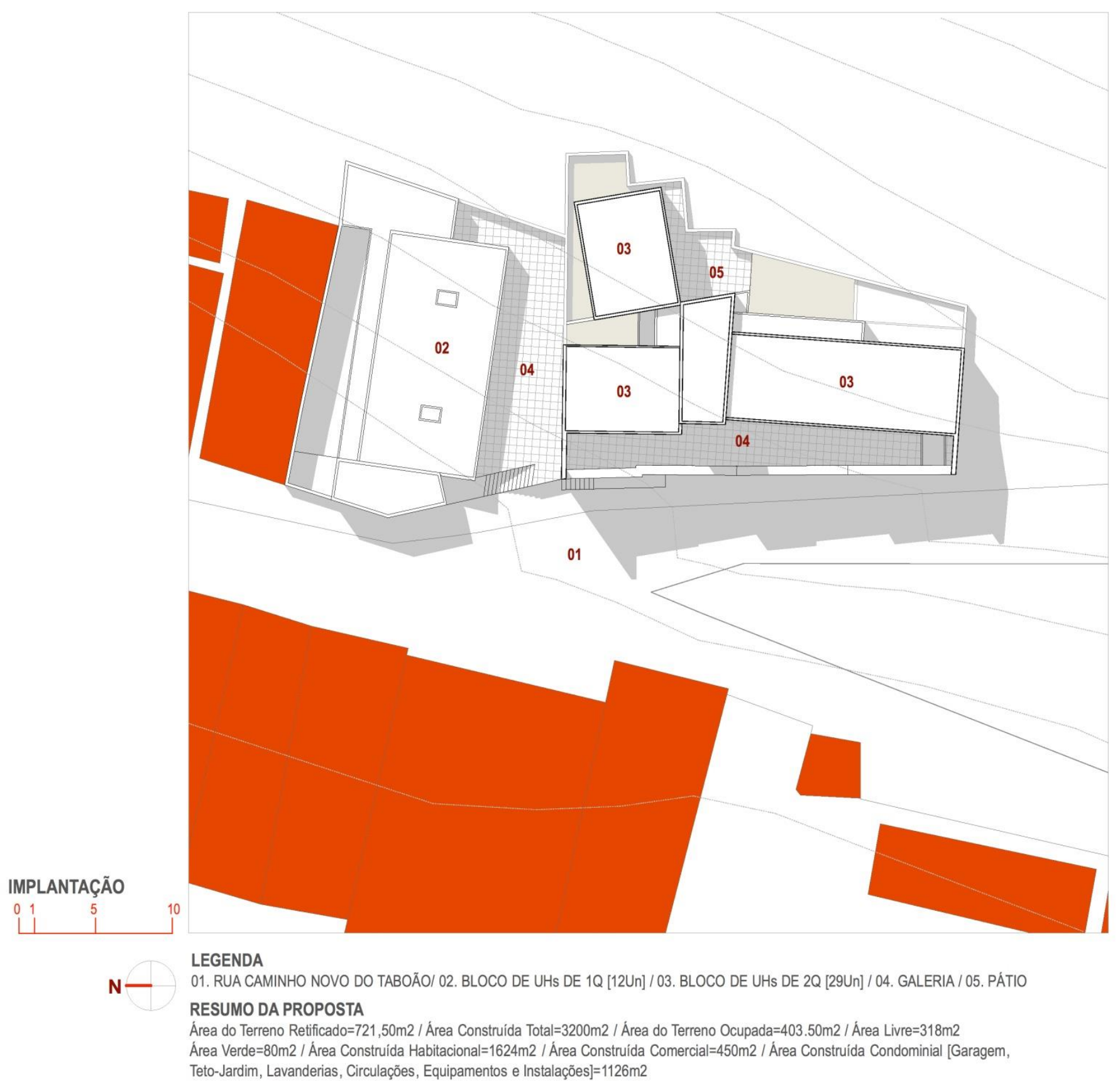

Fonte: Desenho dos autores. 

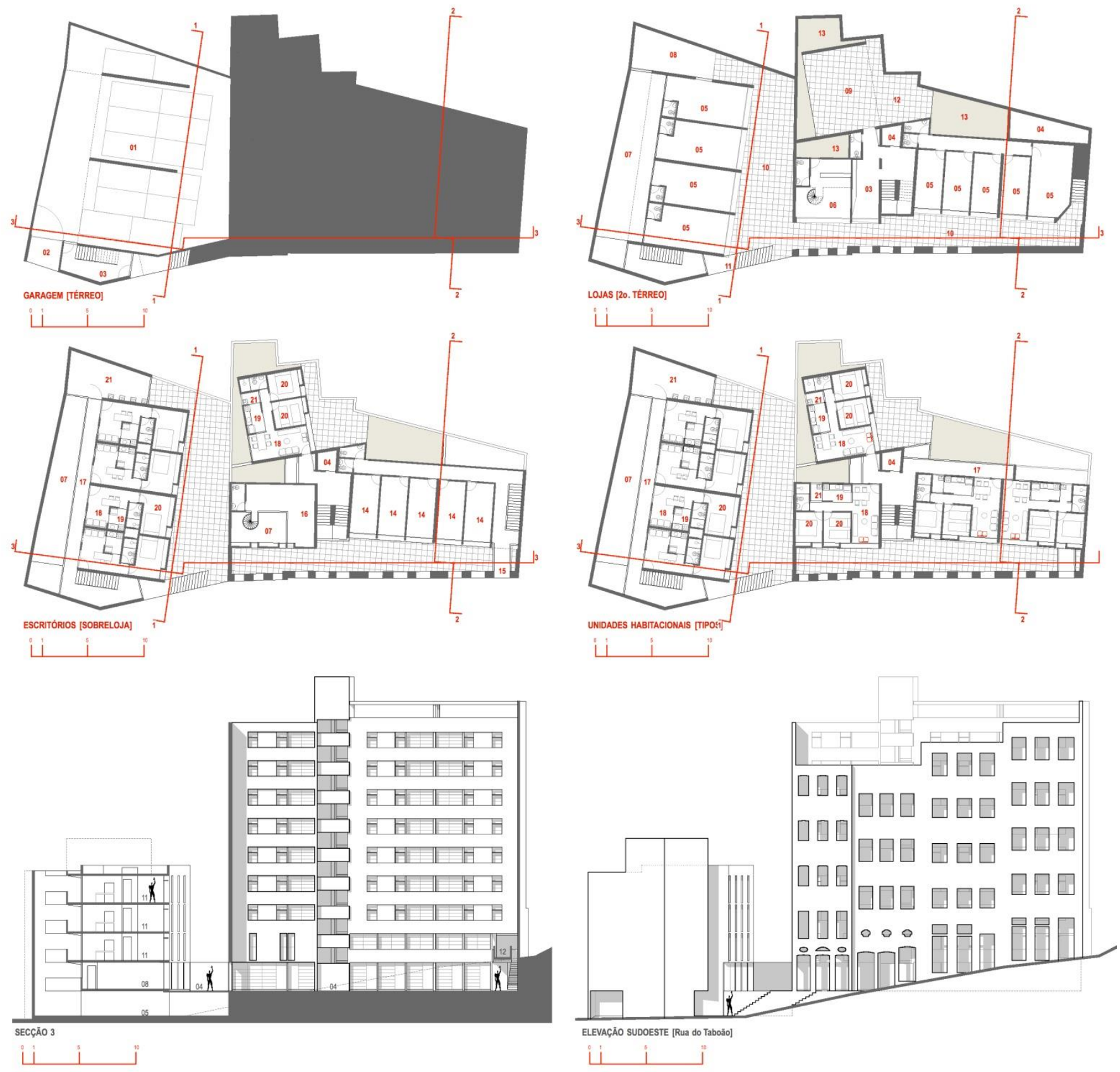

LEGENDA

01. GARAGEM / 02. ACESSO GARAGEM / 03. PORTARIA / 04. ELEVADOR / 05. LOJA / 06. CAFÉ / 07. VAZIO / 08. TERRAÇO COBERTO / 09. SALÄO COMUNAL/ 10. GALERIA / 11. ACESSO GALERIA-ESCADA 12. PÁTIO / 13. JARDINS / 14. ESCRITÓRIO / 15. ACESSO GALERIA.PASSARELA / 16. MEZANINO / 17. CIRCULAÇĀO / 18. SALA DE ESTAR/JANTAR / 19. COZINHA / 20. QUARTO / 21. SERVIÇO 
Medina, L. L.; Lima, A R. S. C.; Albuquerque, T. A. G.; Oliveira, R. C.

Figura 5: Imagens do Painel 3/3 do Concurso
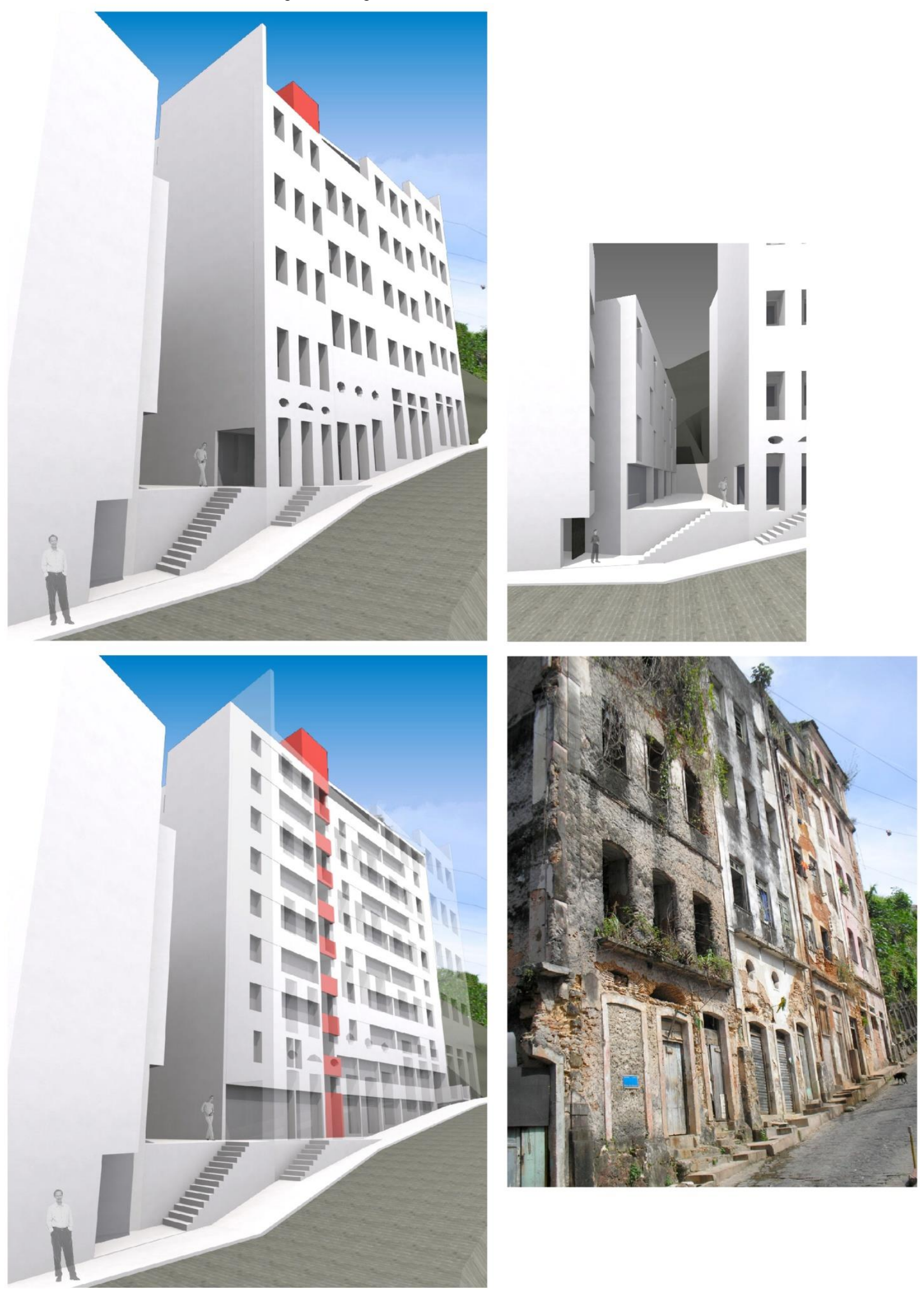

Fonte: Imagens dos autores. 
Medina, L. L.; Lima, A R. S. C.; Albuquerque, T. A. G.; Oliveira, R. C.

Figura 6: Imagens do Painel 3/3 do Concurso
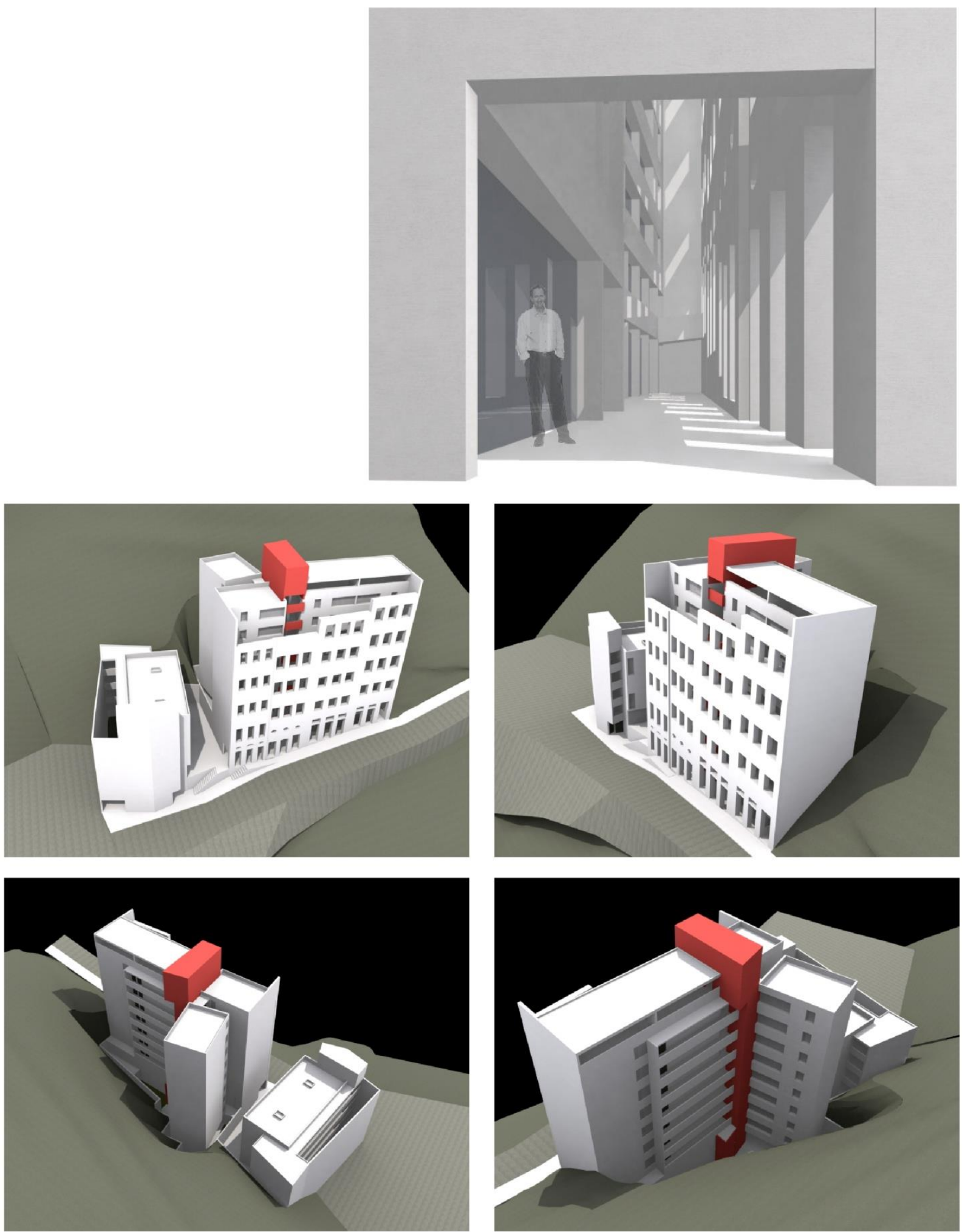

Fonte: Imagens dos autores.

NOTA DO EDITOR (*) O conteúdo do artigo e as imagens nele publicadas são de responsabilidade do(s) autor(es). 